\title{
Freeze-dried bovine amniotic membrane as a cell delivery scaffold in a porcine model of radiation- induced chronic wounds
}

\author{
Daemyung $\mathrm{Oh}^{1}$, Daegu Son ${ }^{1}$, Jinhee Kim ${ }^{2}$, Sun-Young Kwon ${ }^{3}$ \\ Departments of ${ }^{1}$ Plastic and Reconstructive Surgery, ${ }^{2}$ Radiation Oncology, and ${ }^{3}$ Pathology, Keimyung University School of Medicine, Daegu, \\ Korea
}

Background Locoregional stem cell delivery is very important for increasing the efficiency of cell therapy. Amnisite BA (Amnisite) is a freeze-dried amniotic membrane harvested from bovine placenta. The objective of this study was to investigate the retention of cells of the stromal vascular fraction (SVF) on Amnisite and to determine the effects of cell-loaded Amnisite in a porcine radiation-induced chronic wound model.

Methods Initially, experiments were conducted to find the most suitable hydration and incubation conditions for the attachment of SVF cells extracted from pig fat to Amnisite. Before seeding, SVFs were labeled with PKH67. The SVF cell-loaded Amnisite (group S), Amnisite only (group A), and polyurethane foam (group C) were applied to treat radiation-induced chronic wounds in a porcine model. Biopsy was performed at 10,14, and 21 days post-operation for histological analysis.

Results Retaining the SVF on Amnisite required 30 minutes for hydration and 1 hour for incubation. A PKH67 fluorescence study showed that Amnisite successfully delivered the SVF to the wounds. In histological analysis, group S showed increased re-epithelialization and revascularization with decreased inflammation at 10 days post-operation.

Conclusions SVFs had acceptable adherence on hydrated Amnisite, with successful cell delivery to a radiation-induced chronic wound model.

Keywords Amniotic membrane / Cell therapy / Tissue scaffold / Wound healing / Experimental animal model

\author{
Correspondence: Daegu Son \\ Department of Plastic and \\ Reconstructive Surgery, Keimyung \\ University School of Medicine, 1095 \\ Dalgubeol-daero, Dalseo-gu, Daegu \\ 42601, Korea \\ Tel: +82-53-258-7817 \\ Fax: +82-53-258-4590 \\ E-mail: handson@dsmc.or.kr
}

This article was presented at the 7 th R\&R Forum on April 20, 2017, in Daejeon, Korea.

Received: June 3, $2020 \bullet$ Revised: April 6, $2021 \bullet$ Accepted: April 28, 2021

pISSN: 2234-6163・ elSSN: 2234-6171 • https://doi.org/10.5999/aps.2020.00997• Arch Plast Surg 2021;48:448-456

\section{INTRODUCTION}

Chronic wounds can develop in response to arterial and venous insufficiency, diabetes, pressure, and radiation [1]. Radiation injury disrupts all phases of the wound-healing process. In the early stages of radiation injury, erythema, dry desquamation, and hyperpigmentation occur, and in the later stages, tissue fibrosis and blood vessel damage delay healing, causing wounds to become chronic [2].

Chronic wounds are generally difficult to manage using traditional wound management. Cell therapy is an effective method for managing intractable wounds, and several studies have investigated the effects of adipose-derived stem cell (ASC)-mediated wound healing $[3,4]$. However, the use of ASCs for cell therapy 
requires cell expansion in vitro, which is time-consuming and increases the risk of contamination and differentiation [5]. In contrast, the stromal vascular fraction (SVF), a collection of non-expanded heterogeneous cells (mesenchymal stem cells, hematopoietic stem cells, immune cells, fibroblasts, endothelial cells, etc.) derived from enzymatically digested adipose tissue, is easy to isolate and free of ethical concerns. Several studies have demonstrated the potential of SVF as a therapy to improve wounds $[6,7]$.

When SVFs are simply delivered to a wound in solution, rapid diffusion into extracellular fluids results in low cell retention. Jiang et al. [8] loaded SVFs into a three-dimensional collagen scaffold, applied it to a diabetic wound, and reported drastically increased retention and wound healing. In addition, human acellular dermal matrix, hydrogel, chitosan, and porcine small intestinal submucosa matrix have been used as carriers to deliver ASCs [9-12].

Amniotic membranes have long been used in the treatment of burns and have been recently used for tissue engineering due to their structural and biological properties [13]. Amnisite BA (Bioland, Cheonan, Korea) is an acellular bovine amniotic membrane that is stored at room temperature in a freeze-dried state. Storing Amnisite in a freeze-dried state confers stability, longevity, and ease of use while being equivalent in action to that of fresh amniotic membrane [14].

The purpose of this study was to develop a process to retain SVF on Amnisite as a scaffold and to confirm the delivery of SVF to wounds. We also investigated the effects of SVF with Amnisite on radiation-induced chronic wounds in a porcine model.

\section{METHODS}

One 7-month-old female pig weighing $30 \mathrm{~kg}$, in good health and without skin disease, was obtained from Minipig; Medi Kinetics Pyeongtaek, Korea and used for this study. This pig was given standardized feed once daily. It was housed in an isolated room maintained at $24^{\circ} \mathrm{C}$ with $65 \%$ humidity. The Institutional Animal Care and Use Committee approved all experimental procedures (IACUC No. KM-2015-46).

\section{Cellular experiments \\ Isolation of porcine SVF}

At 5 days after the operation, which is described below, adipose tissue was harvested from a 6 -cm-long $\times 4$-cm-wide paraspinous cutaneous flap that was elevated in areas that were not irradiated. Adipose tissue samples were trimmed and transferred to sterile $50 \mathrm{~mL}$ conical tubes that contained $25 \mathrm{~mL}$ of phosphate- buffered saline (PBS). These adipose tissue samples were washed twice with PBS and minced using scissors. The minced adipose tissue had a final volume of roughly $20 \mathrm{~mL}$. The minced adipose tissue samples were subsequently digested with $0.075 \%$ collagenase type I (Worthington Biochemical Corp, Lakewood, $\mathrm{NJ}$, USA) in PBS at $37^{\circ} \mathrm{C}$ for 1 hour under steady moderate agitation. Then, culture medium containing low-glucose Dulbecco's modified Eagle's medium (DMEM) and 10\% fetal bovine serum (FBS) was added to stop enzymatic activity. Centrifugation was performed, after which the supernatant was discarded and the pellet was resuspended and filtered through a $100-\mu \mathrm{m}$ cell strainer to remove tissue debris. The suspension was re-centrifuged at 1,500 rpm for 5 minutes and resuspended in low-glucose DMEM supplemented with $10 \%$ FBS, seeded into $100 \varnothing$ culture dishes, and incubated at $37^{\circ} \mathrm{C}$ with $5 \% \mathrm{CO}_{2}$ for 2 days.

\section{Retention of SVFs on Amnisite BA}

The authors asked the manufacturer to produce Amnisite without a slit and used it in the experiment.

In order to prevent the curling effect that the Amnisite membrane typically exhibits during hydration, PBS was used. To find an efficient hydration time (the shortest time necessary to prevent curling), SVFs $\left(1 \times 10^{6} / \mathrm{cm}^{2}\right)$ were seeded on each of four hydrated Amnisite membranes $\left(1 \times 1 \mathrm{~cm}^{2}\right)$ for 30 minutes, 1 hour, 12 hours, and 24 hours in a dish filled with PBS and then incubated at $37^{\circ} \mathrm{C}$ with $5 \% \mathrm{CO}_{2}$ for 24 hours. Each membrane was then stained with crystal violet and observed using an optical microscope to confirm cell attachment.

To determine the ideal incubation time, SVFs were seeded on Amnisite using the method described above. The membranes were incubated at $37^{\circ} \mathrm{C}$ with $5 \% \mathrm{CO}_{2}$ for $1,3,6,12$, and 24 hours. The success of cell attachment and the bond strength between Amnisite and the SVF were then compared. The ideal incubation time was defined as the time necessary to form a bond strength resilient to just drops of PBS but broken by hydrostatic positive pressure using a pipette. We observed cell attachment using an optical microscope after crystal violet staining.

The success of delivery to the wound and the viability of engrafted cells were evaluated in vivo. Before seeding, SVFs were labeled with PKH67 (PKH67-GL; Sigma-Aldrich, St. Louis, MO, USA). PKH67 labeling was performed in single-cell suspensions containing $0.6-1 \times 10^{7} \mathrm{SVFs}$ that had been washed once in serum-free DMEM. The staining procedure followed the manufacturers' instructions. To summarize, $\mathrm{PKH}$ was added and the cells were mixed by constant inversion of the tube for 5 minutes. Unbound PKH67 molecules were then blocked with $100 \%$ FBS (1:1). The suspension was then centrifuged for 5 minutes at $1,600 \times g$. The supernatant was carefully aspirated 
and cells were resuspended in the culture medium for seeding onto Amnisite.

\section{Animal experiment \\ Delivery of irradiation and wound creation}

A radiation-induced chronic wound model was established following protocols described in previous studies [15,16]. The pig received a single dose of $18 \mathrm{~Gy}$ with a $6 \mathrm{MeV}$ electron beam per $18 \times 8 \mathrm{~cm}$ area. Three radiation areas (total radiation area: 432 $\mathrm{cm}^{2}$ ) were selected on the paraspinal dorsal skin surface of the pig: two were located on the left side of the spine and one was located on the right side of the spine. These areas were selected to ensure sufficient non-radiated tissue around each wound for the areas to stay independent of each other while avoiding the spread of infection and skin necrosis. Over $90 \%$ of the prescribed irradiation dose was limited to a maximum depth of $2 \mathrm{~cm}$.

After 5 weeks of irradiation, a skin defect wound model was designed as follows: First, tiletamine/zolazepam (Zoletil; Virbac, Carros, France) was injected intramuscularly for sedation. Then, xylazine hydrochloride (Rompun; Bayer Animal Health, Monheim, Germany) was injected intravenously for induction. After shaving the hair, a $4 \mathrm{~cm}^{2}$ square excisional wound site was marked with an oil ink pen on the irradiated zone. The site was $2 \mathrm{~cm}$ away from the boundary. A total of six wounds were made. Each wound was positioned $6 \mathrm{~cm}$ apart from the other wounds. The excision tissues included the skin and the superficial fat layer. The deep fat layer was not included to prevent the spread of infection via the muscular fascia (Fig. 1).

\section{Preliminary animal experiment}

A foam dressing (Therasorb, Wonbiogen Co. Ltd., Gumi, Korea) was maintained on the excisional wounds until practical ex-

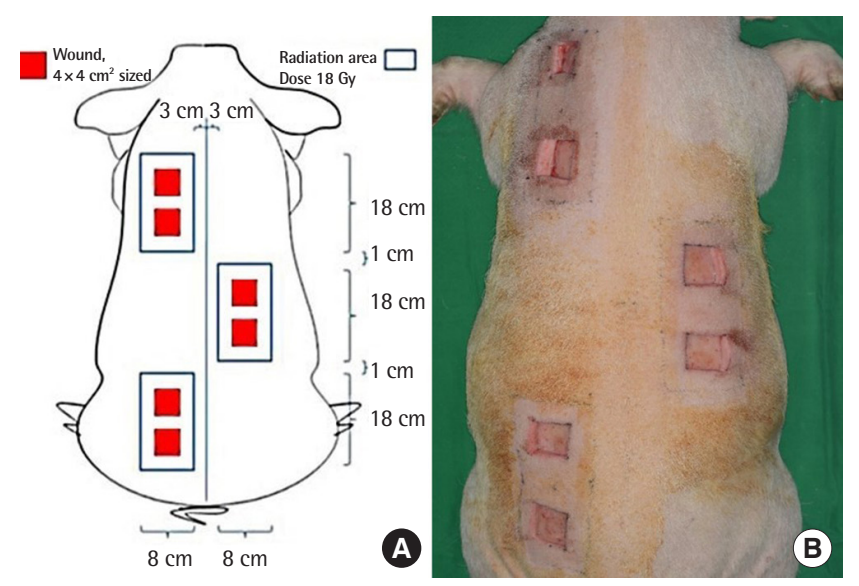

Fig. 1. Wound creation. (A) Diagram of the porcine radiation-induced chronic wound model. (B) Gross findings after creation of chronic wounds. periments. At 7 days post-operation, the wounds were randomly divided into three groups: group S (SVF with Amnisite, $n=2$ ), group A (Amnisite group, $\mathrm{n}=2$ ), and group $\mathrm{C}$ (control group, Therasorb, $\mathrm{n}=2$ ) (Fig. 2). In group $S, 1 \times 10^{6} / \mathrm{cm}^{2} S V F$ suspended in Amnisite was applied to the wounds, which were then covered with Vaseline gauze and polyurethane foam. In group A, Amnisite was applied to wounds dressed with the same method used for those in group S. In group C, only polyurethane foam was applied to wounds. The body of the pig was then covered with a snug-fitting non-adherent tube gauze dressing (Tubifast; Mölnlycke Health Care, Gothenburg, Sweden), which was tailored into a vest to further protect wounds.

\section{Measurement of wound contraction}

To compare the rate of wound contraction ([original wound size (at 7 days post-operation)-wound size measured at that time/original wound size] $\times 100$ ) among the three wound groups, photographs of the wound region were obtained with a digital camera every time dressings were changed. These photographs were analyzed using ImageJ software (National Institutes of Health, Bethesda, MD, USA). All photographs were taken with a sterilized paper ruler that was used for calibration, standardization, and subsequent quantitative analysis.

\section{Histological analysis}

Biopsies were taken sequentially from each of three sides of the square at 10,14, and 21 days post-operation. The specimens were full-thickness incisional biopsy specimens (including skin, superficial and deep subcutaneous tissue, and granulation tissue)

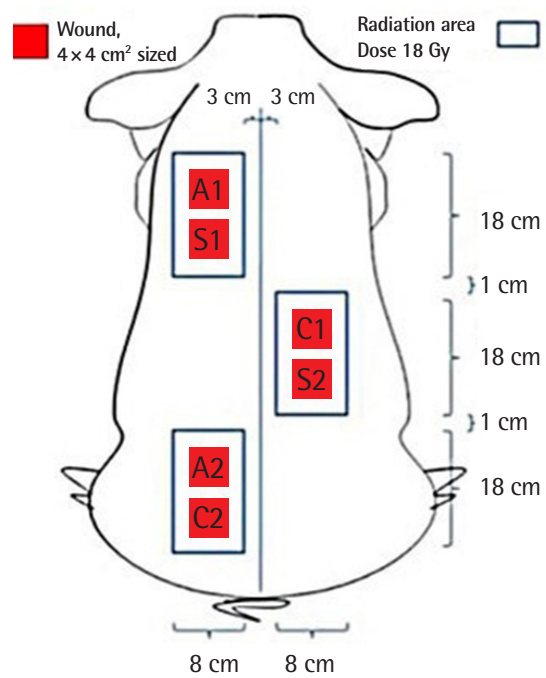

Fig. 2. Diagram showing locations of dressing application areas. S1, S2: stromal vascular fraction with amniotic membrane (AM) application; A1, A2: AM application; C1, C2: control group, Therasorb application. 
at the margin of the wound. They were $5 \mathrm{~mm}$ wide and $10 \mathrm{~mm}$ long, and included approximately $4 \mathrm{~mm}$ of unwounded skin. All tissue samples were fixed in $10 \%$ neutral buffered formalin.

All scoring and interpretations of the immunohistochemical results were performed by one examiner without knowledge of the clinical data. For the histological analysis, hematoxylin-eosin staining was used to determine the grade of inflammation grade and degree of re-epithelialization. The severity of acute and chronic inflammation was graded (mild, 1; moderate, 2 ; severe, $3)$. Neutrophils and eosinophils were considered to indicate acute inflammation, whereas the presence of lymphocytes and plasma cells was deemed to be a sign of chronic inflammation. The degree of re-epithelialization was categorized as 0 (none), 1 (incomplete epithelialization, in less than half of the wound), and 2 (more than half to complete epithelialization). The neovascularization level of wound granulation tissues was evaluated by immunochemical analysis using CD-31 staining. Sections were scanned at a low magnification $(x 40)$. Areas with the highest concentration of microvessels (vascular hot spots) were selected in each biopsy specimen. In each selected area, five high-magnification fields $(\times 400)$ were evaluated and the average of all counted microvessels (mean microvessel density) was calculated [17].

\section{RESULTS}

We observed that hydrating Amnisite for 30 minutes enabled the retention of cells and prevented curling (Fig. 3). In addition, we found that incubating Amnisite with the SVF for 1 hour resulted in successful cell attachment with appropriate bond strength (Fig. 4). Successful delivery of the SVF to wounds was observed with a fluorescence microscope. In group S, the PKH67-labeled SVF released specific green fluorescence in every biopsy specimen (Fig. 5).

Compared with the other two groups, group A showed a markedly higher wound contraction rate. Group S demonstrated the lowest wound contraction rate. No group healed completely during the experimental periods (Fig. 6).

On day 10, the re-epithelialization scores were 0 in groups $\mathrm{A}$ and $\mathrm{C}$, and 1 in group $\mathrm{S}$. The re-epithelialization scores were 1 , 1.5 , and 0.5 in groups A, S, and C on day 14 , respectively. However, there was no difference in the re-epithelialization score (1.5) between any group on day 21. At 10 days post-operation, group S showed early re-epithelialization, while the other groups did not. Re-epithelialization increased in group $\mathrm{S}$ until 14 days post-operation, and then remained constant (Fig. 7).

The acute inflammation scores on day 10 were $1.5,1.5$, and 2 in groups $\mathrm{S}, \mathrm{A}$, and $\mathrm{C}$, respectively. On day 14 , the acute inflam-
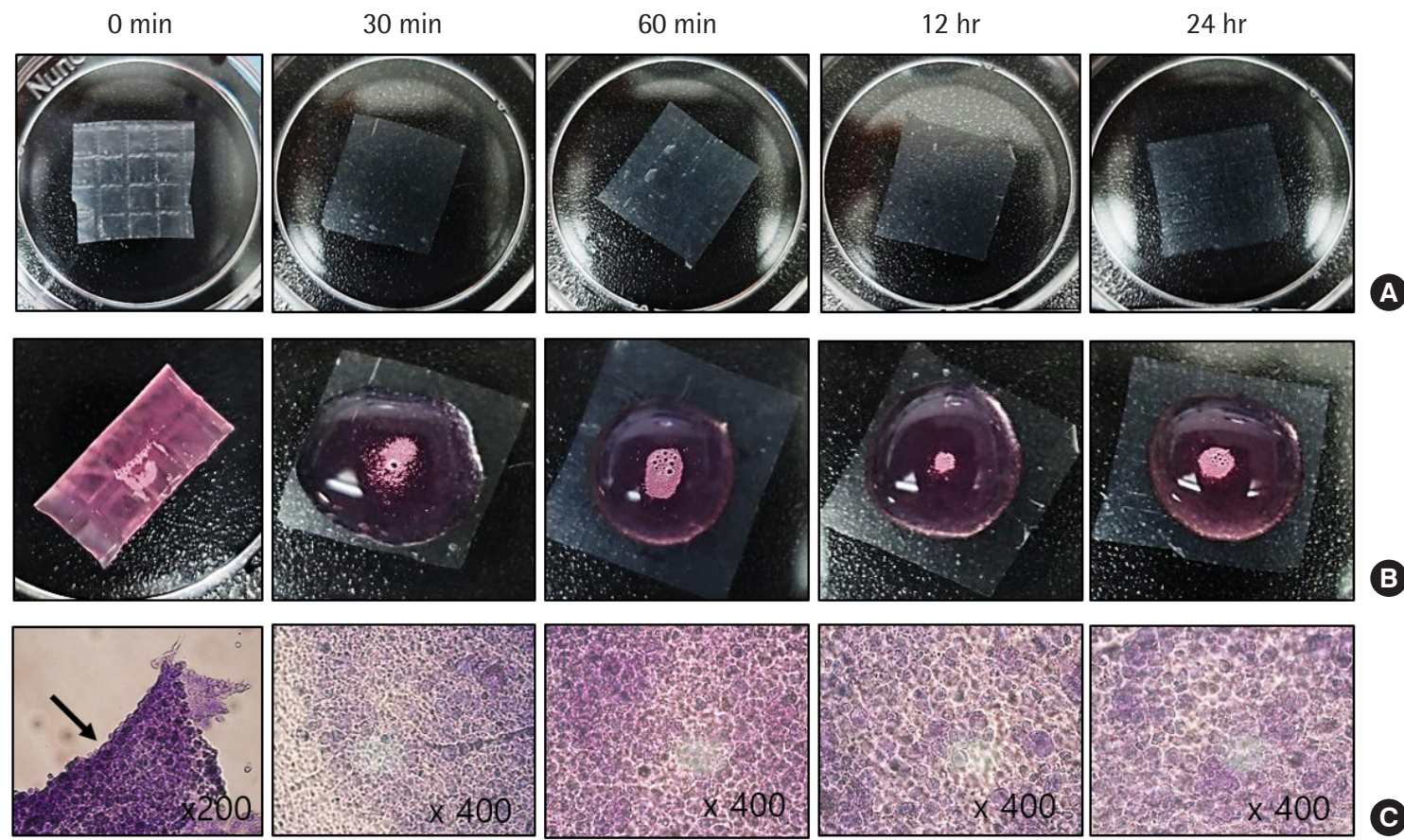

B

Fig. 3. Stromal vascular fraction retention over hydration time. (A) Gross findings of the amniotic membrane (AM) $\left(1 \times 1 \mathrm{~cm}^{2}\right)$ according to hydrating time. (B) When seeding stromal vascular fractions $\left(1 \times 10^{6} / \mathrm{cm}^{2}\right)$ on each membrane, the dried AM ( 0 minutes) curled due to surface tension, whereas the AM hydrated for at least 30 minutes appeared flat without any curling effect. (C) Microscopic findings after incubation at $37^{\circ} \mathrm{C}$ with $5 \% \mathrm{CO}_{2}$ for 24 hours (crystal violet stain): although 0 minutes showed aggregated and floating cells (arrow) without attaching to the AM, other groups showed well-attached cells. 

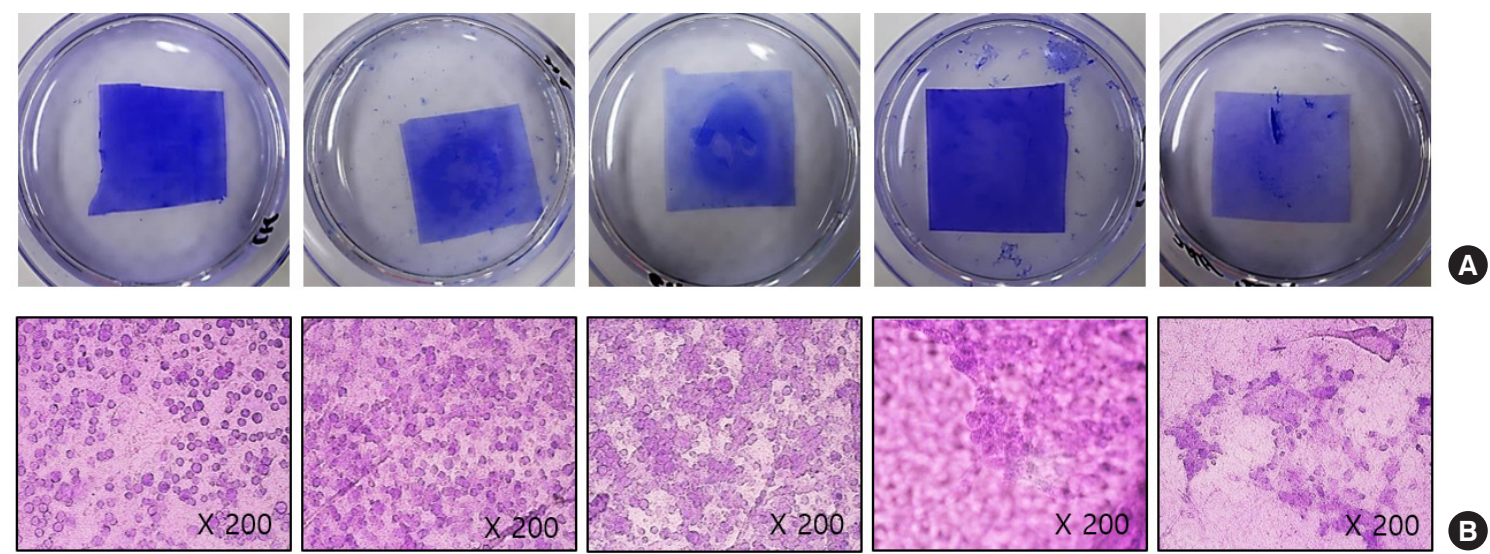

Fig. 4. Stromal vascular fraction (SVF) retention according to incubation time. (A) Gross findings of amniotic membrane $(\mathrm{AM})\left(1 \times 1 \mathrm{~cm}^{2}\right) \mathrm{seeded}$ SVFs $\left(1 \times 10^{6} / \mathrm{cm}^{2}\right)$ and stained with crystal violet according to incubating time. (B) Microscopic finding after incubation at $37^{\circ} \mathrm{C}$ with $5 \% \mathrm{CO}_{2}$ (crystal violet stain): incubating AM with SVF for 1 hour resulted in successful cell attachment without a definite difference compared to other groups.

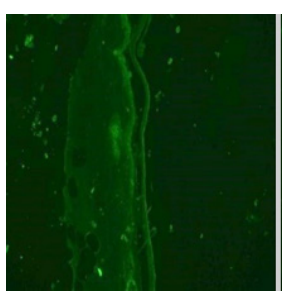

10 Days

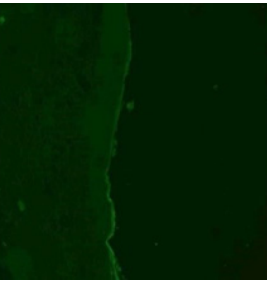

14 Days

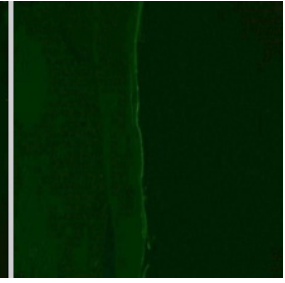

21 Days

Fig. 5. Delivery of stromal vascular fraction to wounds. Live PKH67labeled stromal vascular fraction emitting green fluorescence in specimens excised at 10 days, 14 days, and 21 days post-operation.

mation score was the highest in group A, at 2.5. The acute inflammation score on day 21 was the lowest in group $\mathrm{C}$, at 0.5 . Acute inflammation was the lowest in group $\mathrm{S}$ until 14 days post-operation. Instead of showing acute inflammation, group $S$ had the highest chronic inflammation score at 10 days post-operation. This score decreased until day 14 , but fat necrosis increased and foreign body giant cells were still present. On the 21 st day, the chronic inflammation score was the same in all groups, at 1.5 (Fig. 8).

On the 10th day, the microvascular density was highest in group S, at 7.7, but by the 14th day, group A was highest, at 11.05. By the 21st day, both groups had stabilized and the densities were well matched (Figs. 9 and 10).

\section{DISCUSSION}

Fresh human amniotic membrane has been widely used for wound dressings [18]. However, a disadvantage of fresh amniotic membrane is that it is difficult to store. Freeze-dried amniotic membrane is a ready-to-use product with all advantages of fresh human amnion, but without its disadvantages [14]. Some

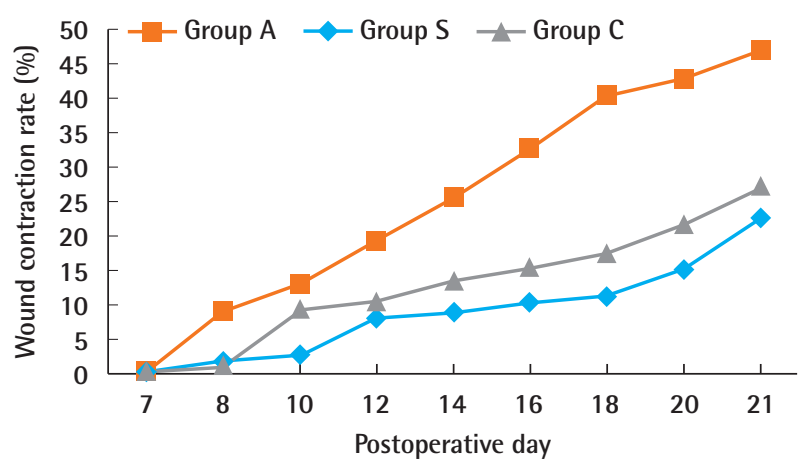

Fig. 6. Wound contraction rate. The wound contraction rate ([original wound size-wound size measured at that time /original wound size] $\times 100$ ) was highest in group $A$ and lowest in group $S$. Group $A$, Amnisite group; Group S, SVF with Amnisite; Group C, control group.

ready-to-use products derived from freeze-dried amniotic membrane are currently available, such as Amnisite BA and Biovance (Alliqua BioMedical, Langhorne, PA, USA) [19]. These products were mainly developed for skin or corneal dressings; however, since amniotic membrane contains growth factors with anti-inflammatory and anti-microbial effects, it also makes an effective scaffold. There are a number of other advantages to using amniotic membrane as a scaffold. First, the membrane has an extracellular matrix, which allows cell adhesion and growth. Additionally, amniotic membrane has plasticity and other biological properties, including several growth factors with anti-inflammatory and anti-microbial effects [13].

For cell therapy, attaching cells to the scaffold is a significant step. Cell seeding is the first step in cell adhesion, and its efficiency and distribution affect the final outcome. Gholipourmalekabadi et al. [20] seeded human ASCs on a decellularized human amniotic membrane and incubated it at $37^{\circ} \mathrm{C}$ with $5 \%$ $\mathrm{CO}_{2}$ for 1, 2, 3, and 7 days. Mahmoudi-Rad et al. [21] showed 

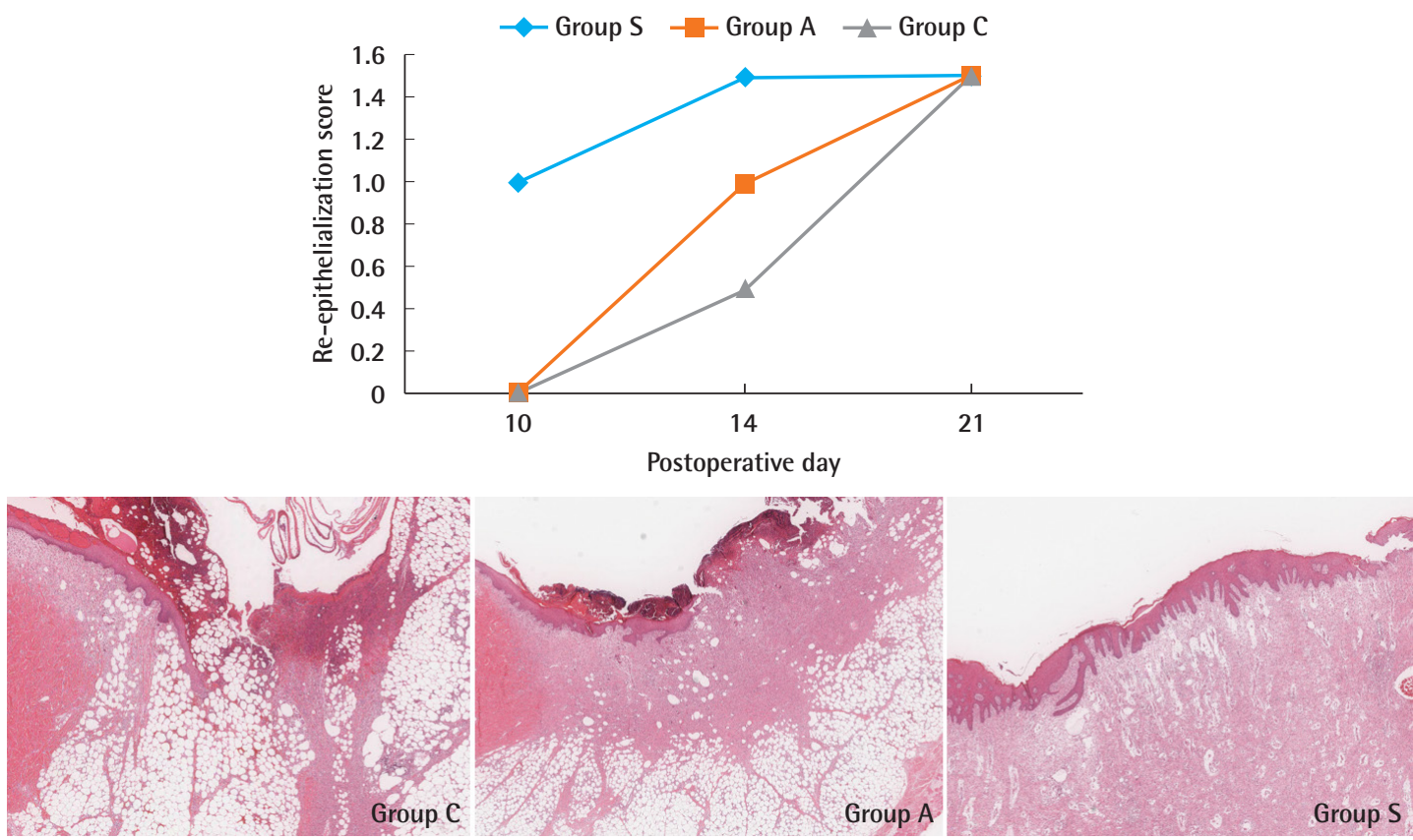

Fig. 7. Re-epithelialization score. At 10 days post-operation, group S was the only group that showed early re-epithelialization. At 21 days post-operation, all groups showed similar results. Histological findings of epithelialization at 14 days. The degree of re-epithelialization was incomplete (less than half of the wounds) in group $\mathrm{C}$ and group $\mathrm{A}\left(\mathrm{H} \& \mathrm{E}_{1} \times 40\right)$. In group $\mathrm{S}$, re-epithelialization was more than half to complete $(H \& E, \times 40)$. Group A, Amnisite group; Group S, SVF with Amnisite; Group C, control group.
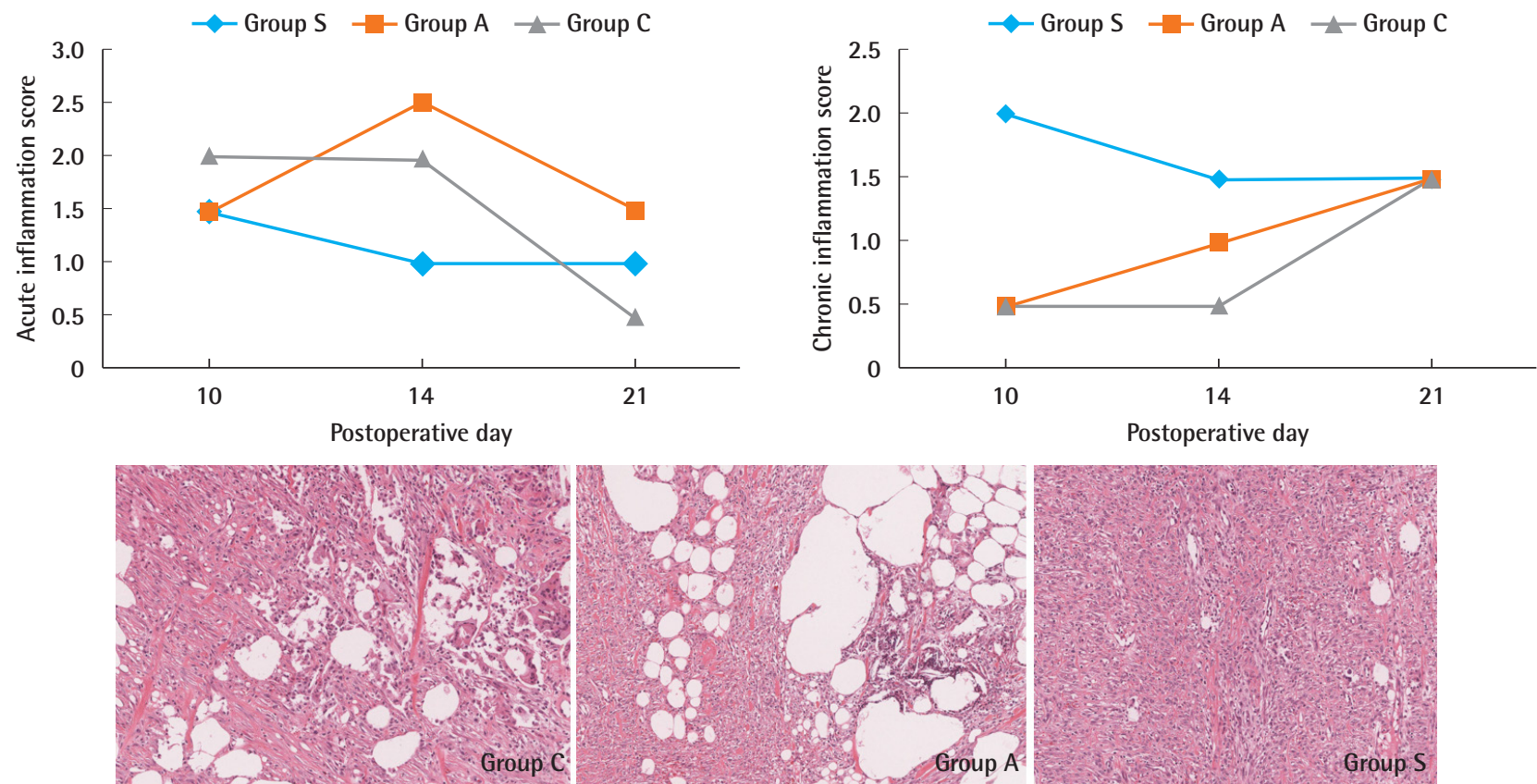

Fig. 8. Inflammation scores. Acute and chronic inflammation in group S decreased until 14 days post-operation and then remained constant. Degree of inflammation at 14 days; significant chronic inflammation remained and foreign body giant cells significantly increased with fat necrosis in group $C$ and group $A\left(H \& E_{1} \times 100\right)$. Chronic inflammatory cells and giant cells decreased in group $S\left(H \& E_{1} \times 100\right)$. Group $A, A m n i s i t e$ group; Group S, SVF with Amnisite; Group C, control group.

excellent growth of allogenic fibroblasts on an acellular amniotic membrane scaffold, which they produced and incubated for 24 hours. Diaz-Prado et al. [22] seeded human chondrocytes on a cryopreserved human amniotic membrane and incubated it for
3-4 weeks. They then used this membrane to support chondrocyte proliferation for transplantation therapy to repair osteoarthritis cartilage in vitro. While the purposes of those experiments were different from the purpose of the present study, the 
processes of preparing the amnion scaffold and incubating the cell-scaffold complex took one day to several days. In addition, the prior studies were all conducted in vitro, without confirming whether actual cells were delivered in vivo. In contrast, we completed amnion scaffold preparation, cell seeding, and incubation in a total of 90 minutes and confirmed cell viability and successful attachment of SVF to Amnisite. Furthermore, we confirmed successful cell delivery to radiation-induced chronic wounds using an in vivo experiment. In clinical practice, the authors' method can be used to harvest and process cells at the start of surgery. These cells can then be loaded into the scaffold and delivered to

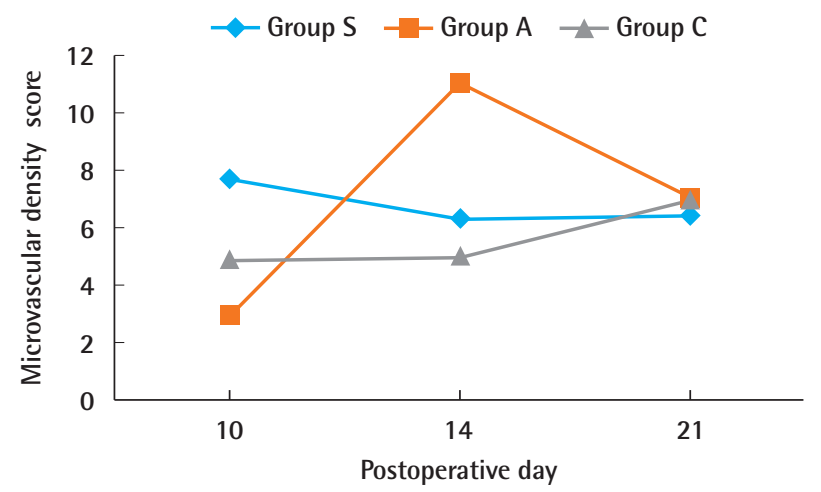

Fig. 9. Microvascular density score. Group S showed the highest level of revascularization at 10 days post-operation. This effect then gradually decreased until 21 days post-operation, when group $S$ showed the least revascularization among the three groups. Group $A$, Amnisite group; Group S, SVF with Amnisite; Group C, control group. the wound at the end of surgery.

Cell delivery was confirmed in preliminary animal experiments, but improved wound healing through the use of cellloaded Amnisite was not confirmed. Histopathological examinations showed that the SVF had positive effects on re-epithelialization until 14 days post-operation, without significant changes thereafter. These positive effects of SVF might gradually decrease, with SVF losing its effectiveness after 14 days postoperation. This change might be due to the anti-inflammatory effect of SVF, which promotes revascularization [23,24].

The epithelialization at the wound edge was better in group $S$ than in group $\mathrm{A}$, but the wound contraction was better in group A. The acute inflammation score was lower in group $S$ than in group A, but the chronic inflammation score was higher in group $S$ than in groups $A$ and $C$. These results suggest that SVFloaded Amnisite temporarily reduces acute inflammation and promotes epithelialization at the beginning of application, but its effect does not last long. Moreover, since radiation-induced chronic wounds already have many chronic inflammatory cells and have limitations in extracellular matrix production and wound contraction, it was difficult to analyze and interpret the results.

As this was only a preliminary in vivo experiment, there are some limitations. The sample size of animals was small $(n=2)$. In order to better elucidate the effectiveness of cell therapy on radiation-induced chronic wounds, the timing and conditions of cell therapy should be planned in more detail. Even a single

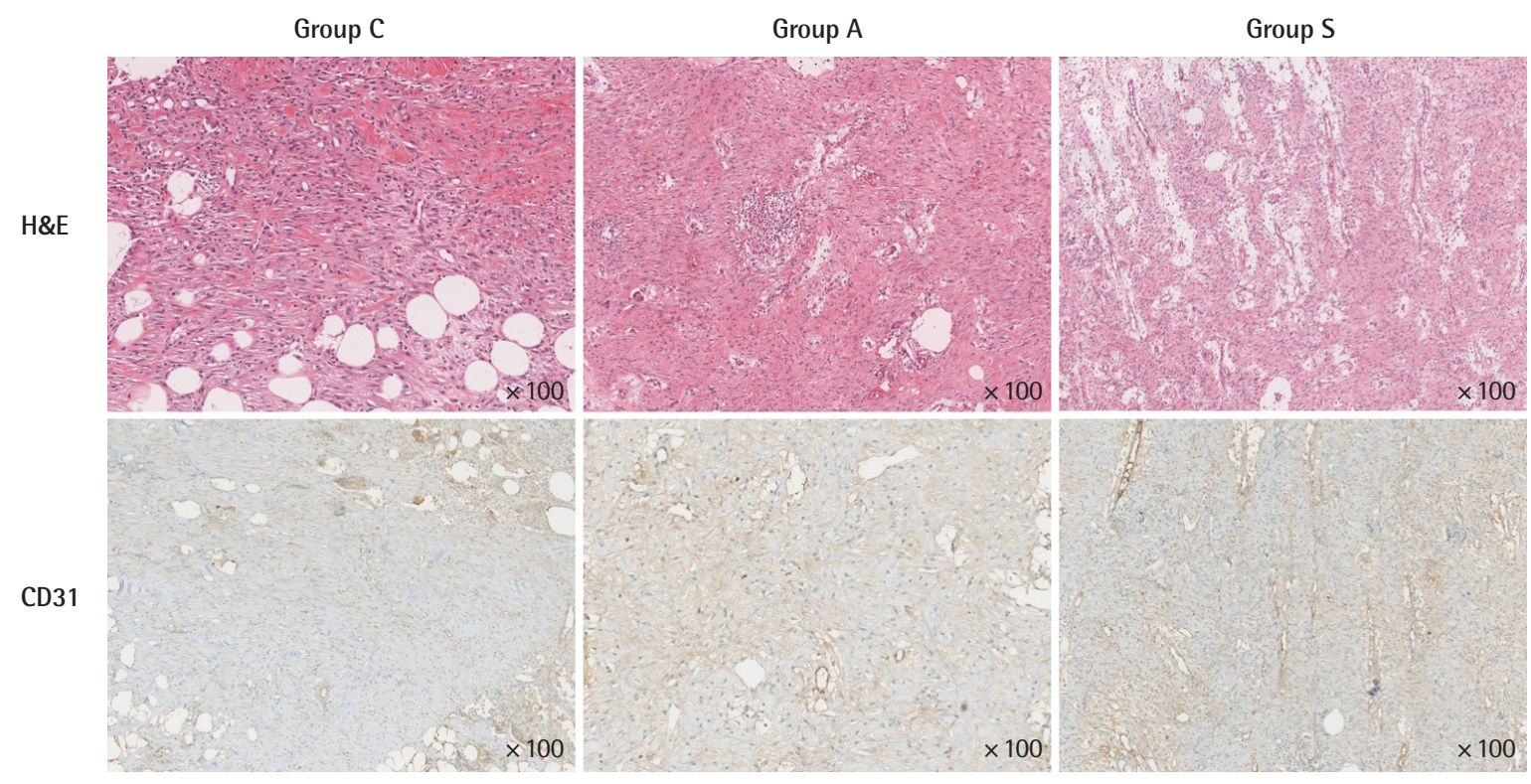

Fig. 10. Histological and immunohistochemical findings of microvascular density at 10 days. In group $C$, slightly increased vascular structures with retained acute and chronic inflammatory cells. In group A, inflammatory cells slightly increased but the number of vessels did not increase compared to group $\mathrm{C}$. In group $\mathrm{S}$, markedly increased vascular density was noted, with remarkably reduced inflammatory cells in the stroma. Group A, Amnisite group; Group S, SVF with Amnisite; Group C, control group. 
cell delivery would have been insufficient to make a difference. In addition, the histological grading of the wound must be based on the meticulous assessment of different parameters according to each wound healing phase to assess the wound status accurately [25].

As far as the authors are aware, this is the first study providing evidence for the effectiveness of freeze-dried bovine amniotic membrane as a scaffold for cell delivery. In this preliminary study, we developed a process to retain SVF on an amniotic membrane as a scaffold and confirmed the delivery of SVF to radiation-induced chronic wounds in a porcine model. We demonstrated that SVFs had acceptable adherence on freezedried bovine amniotic membranes, showing that this complex can potentially be an effective scaffold with a high level of convenience for soft tissue engineering applications.

\section{NOTES}

\section{Conflict of interest}

No potential conflict of interest relevant to this article was reported.

\section{Ethical approval}

Animal testing was conducted in accordance with the ethical standards of the Institutional Animal Care and Use Committee of Keimyung University (IACUC No. KM-2015-46).

\section{Author contribution}

Conceptualization: D Son. Formal analysis: D Oh, D Son, SY Kwon. Methodology: D Oh, D Son, J Kim. Project administration: D Son. Writing - original draft: D Oh. Writing - review \& editing: D Son.

\section{ORCID}

Daemyung $\mathrm{Oh}$

https://orcid.org/0000-0003-1305-2099

Daegu Son https://orcid.org/0000-0002-4653-1048

Jinhee Kim https://orcid.org/0000-0001-8608-9250

Sun-Young Kwon

https://orcid.org/0000-0002-8410-0185

\section{REFERENCES}

1. Sen CK, Roy S. Wound healing. In: Gunter GC, Neligan PC, editors. Plastic surgery. 3rd ed. London: Elsevier Saunders; 2013. p. 253-6.

2. Bernstein EF, Harisiadis L, Salomon GD, et al. Healing impairment of open wounds by skin irradiation. J Dermatol Surg Oncol 1994;20:757-60.

3. Chen YW, Scutaru TT, Ghetu N, et al. The effects of adi- pose-derived stem cell-differentiated adipocytes on skin burn wound healing in rats. J Burn Care Res 2017;38:1-10.

4. Kato Y, Iwata T, Morikawa S, et al. Allogeneic transplantation of an adipose-derived stem cell sheet combined with artificial skin accelerates wound healing in a rat wound model of type 2 diabetes and obesity. Diabetes 2015;64: 2723-34.

5. Sheng L, Yang M, Li H, et al. Transplantation of adipose stromal cells promotes neovascularization of random skin flaps. Tohoku J Exp Med 2011;224:229-34.

6. Bourin P, Bunnell BA, Casteilla L, et al. Stromal cells from the adipose tissue-derived stromal vascular fraction and culture expanded adipose tissue-derived stromal/stem cells: a joint statement of the International Federation for Adipose Therapeutics and Science (IFATS) and the International Society for Cellular Therapy (ISCT). Cytotherapy 2013;15: 641-8.

7. Gimble JM, Katz AJ, Bunnell BA. Adipose-derived stem cells for regenerative medicine. Circ Res 2007;100:1249-60.

8. Jiang Y, Chen B, Liu Y, et al. Effect of collagen scaffold with adipose-derived stromal vascular fraction cells on diabetic wound healing: a study in a diabetic porcine model. Tissue Eng Regen Med 2013;10:192-9.

9. Altman AM, Matthias N, Yan Y, et al. Dermal matrix as a carrier for in vivo delivery of human adipose-derived stem cells. Biomaterials 2008;29:1431-42.

10. Allbright KO, Bliley JM, Havis E, et al. Delivery of adiposederived stem cells in poloxamer hydrogel improves peripheral nerve regeneration. Muscle Nerve 2018;58:251-60.

11. Cheng NC, Lin WJ, Ling TY, et al. Sustained release of adipose-derived stem cells by thermosensitive chitosan/gelatin hydrogel for therapeutic angiogenesis. Acta Biomater 2017; 51:258-67.

12. Choi JS, An HY, Shin HS, et al. Enhanced tissue remodelling efficacy of adipose-derived mesenchymal stem cells using injectable matrices in radiation-damaged salivary gland model.J Tissue Eng Regen Med 2018;12:e695-706.

13. Niknejad H, Peirovi H, Jorjani M, et al. Properties of the amniotic membrane for potential use in tissue engineering. Eur Cell Mater 2008;15:88-99.

14. Park M, Kim S, Kim IS, et al. Healing of a porcine burn wound dressed with human and bovine amniotic membranes. Wound Repair Regen 2008;16:520-8.

15. Jeong W, Oh D, Kwon S, et al. Induction of delayed wound healing by irradiation with optional mechanical compression in swine. J Tissue Viability 2016;25:237-43.

16. Yang X, Jeong W, Son D, et al. Establishment of an uncomplicated radiation-delayed wound healing model using irra- 
diation in pigs. Wounds 2019;31:59-64.

17. Cheong H, Kang H, Kim HK, et al. Microvessel and lymphatic vessel density and VEGFR-3 expression of papillary thyroid carcinoma with comparative analysis of clinicopathological characteristics. Korean J Pathol 2010;44:243-51.

18. Mohammadi AA, Seyed Jafari SM, Kiasat M, et al. Effect of fresh human amniotic membrane dressing on graft take in patients with chronic burn wounds compared with conventional methods. Burns 2013;39:349-53.

19. Smiell JM, Treadwell T, Hahn HD, et al. Real-world experience with a decellularized dehydrated human amniotic membrane allograft. Wounds 2015;27:158-69.

20. Gholipourmalekabadi M, Sameni M, Radenkovic D, et al. Decellularized human amniotic membrane: how viable is it as a delivery system for human adipose tissue-derived stromal cells? Cell Prolif 2016;49:115-21.

21. Mahmoudi-Rad M, Abolhasani E, Moravvej H, et al. Acellu- lar amniotic membrane: an appropriate scaffold for fibroblast proliferation. Clin Exp Dermatol 2013;38:646-51.

22. Diaz-Prado S, Rendal-Vazquez ME, Muinos-Lopez E, et al. Potential use of the human amniotic membrane as a scaffold in human articular cartilage repair. Cell Tissue Bank 2010; 11:183-95.

23. Gentile P, Orlandi A, Scioli MG, et al. Concise review: adipose-derived stromal vascular fraction cells and platelet-rich plasma: basic and clinical implications for tissue engineering therapies in regenerative surgery. Stem Cells Transl Med 2012;1:230-6.

24. Dykstra JA, Facile T, Patrick RJ, et al. Concise review: fat and furious. Harnessing the full potential of adipose-derived stromal vascular fraction. Stem Cells Transl Med 2017;6: 1096-108.

25. Gupta A, Kumar P. Assessment of the histological state of the healing wound. Plast Aesthet Res 2015;2:239-42. 